\title{
Implementing Sustainable Construction Principles and Practices by Key Stakeholders
}

\author{
Nnamdi MADUKA ${ }^{1}$, David GREENWOOD ${ }^{2}$, Allan OSBORNE $^{3}$ and Chika UDEAJA ${ }^{4}$ \\ ${ }^{I}$ Doctoral Student, Department of Mechanical and Construction, Northumbria University, Newcastle \\ upon Tyne, NE1 8ST, United Kingdom2 \\ ${ }^{3}$ Professor of Construction Management, Department of Mechanical and Construction, Northumbria \\ University, Newcastle upon Tyne, NE1 8ST, United Kingdom \\ ${ }^{3}$ Senior Lecturer, Department of Mechanical and Construction, Northumbria University, Newcastle upon \\ Tyne, NE1 8ST, United Kingdom \\ ${ }^{4}$ Senior Lecturer, Department of Construction Project Management, University of Salford, Manchester, M5 \\ 4WT, United Kingdom \\ Email:nnamdi.maduka@northumbria.ac.uk
}

\section{ABSTRACT}

The term 'sustainable construction' is used to highlight the responsibility of the construction industry in attaining sustainable development (SD). With the increasing necessity for resource efficiency and climate change adaptation, there is a need for construction key stakeholders to implement sustainable principles and practices in construction projects. In the UK context, engaging in such action will facilitate the government target of $80 \%$ greenhouse gas reduction by 2050 and also be a potential source of competitive advantage in the future. The aim of this study is to examine how the industry values and promotes sustainable principles and practices in construction projects. A quantitative research method was adopted in order to reach a wider audience in the industry. An online questionnaire survey was used to collect data. The key finding from the survey is that the level of construction industry promotion of sustainable principles and practices is less than it should be. The outcome of the survey suggests that the industry needs to strategise on how to champion and promote the implementation of sustainable principles and practices at a greater level if the industry is to contribute to the global quest for SD.

KEYWORDS: Sustainable construction; SD; Key stakeholders; sustainable principles and practices.

INTRODUCTION: Sustainable construction (SC) can be considered as a subset of Sustainable Development (SD) in which economic growth and social progress for all is combined with effective protection of the environment and prudent use of resources. SC is becoming so important largely because of concerns about damage to our environment through climate change brought about by global warming, and recognition that natural resources are predetermined. This is further emphasised by the rapid economic growth in a number of highly populated areas of the world, significantly increasing the potential environmental impact globally. Construction has been identified as being particularly important because of the significant environmental and social impacts which the built environment has on everyone's quality of life (Petri, 2014). Existing research shows that construction activities have a significant impact on the environment (Hill and Bowen, 1997, Shellbourn et al., 2006, Petri, 2014). Consequently, the construction industry is under pressure to increase the sustainability of its principles and practices in construction projects, the implication of which is a requirement on the industry's behalf to understand the demands both from society and its clients, and its sense of corporate responsibility, which in turn implies major changes in its working practices (Rezgui and Miles, 2011). From a sustainability perspective where balancing economic, environmental and social aspects are important, it 
is imperative that the key stakeholders in the construction industry implement sustainable principles and practices into construction activities in order to achieve sustainable development (SD). Yudelson (2010) stated that stakeholders in this context are people who directly or indirectly have a vested interest in the building, its operation, and future outcome. The author further stated that construction key stakeholders can include the owner, tenants, investors, building operator, and the designers etc. Key stakeholders play important roles in promoting SD within the context of the construction industry by assuming the responsibility to minimise the negative impacts of construction on the environment and society while maximising its economic contribution. Therefore, need for the key stakeholders in the construction industry to champion and improve sustainable practices and principles cannot be over-emphasised if the government can achieve its 2050 target. This paper examines the level of interest by the key stakeholders in sustainable principles and practices in the industry in order achieve the needed SD through sustainable construction.

LITERATURE REVIEW: SC refers to the integration of environmental, social and economic considerations into construction business strategies and practices. It is the application of the principles of SD to the comprehensive construction cycle from the extraction of raw materials, through the planning, design and construction of buildings and infrastructure, until their final deconstruction and management of the resultant waste (Pitt et al., 2009). SC is seen as a way for the construction industry to contribute its quota to achieving SD (Maduka et al., 2015a). Since the construction industry has a great impact on the environment, the need for improvements in environmental, social and economic performance in construction is imperative (Maduka et al., 2015b). In pursuing SC principles and practice, a great deal of research has been done (Kibert, 2008). It is important for construction practitioners and key stakeholders to understand SC sufficiently to be able to ensure that their individual actions and the decisions they make will influence the actions of others in achieving SD (Parkin, 2000). It is argued that although many construction stakeholders agreed with sustainability principles and practices, however, many have still not understood their meaning and very few have translated sustainability into action (Shellbourn et al., 2006). Implementing SC involves integrating all of the principles of SC into the construction activities of the project life cycle, with every stakeholder having a responsibility for carrying out sustainability practices (Hill and Bowen, 1997). Shen et al. (2008) argued that every stakeholder makes specific contributions to improving sustainability, while owners play a critical role in requiring other stakeholders to adopt SC practices (Fadeyi et al., 2012). Usually, clients are the demanders in the construction projects, their willingness and their needs shape the products and process from the very beginning of construction projects to the end (Pitt et al., 2009). By incorporating sustainability principles from the start of their projects, the client consequent decision-making and practices are more likely to promote SC (Abidin, 2010). In other words, the real driving force for SC can come from the key stakeholders, particularly the clients (Shen et al., 2010). Despite clients being regarded as key drivers and stakeholders of SC, the lack of attention to their demands and requirements has been considered as one of the main barriers to achieving SC (Pitt et al., 2009). Construction stakeholders worldwide are beginning to appreciate sustainability and acknowledge the advantages of SC. Global interest in sustainability has steadily increased, however, in the construction industry the level of sustainable principles and practices implementation is believed be low (Brownhill and Rao, 2002). It is essential to understand that in developing the regulatory environment to meet carbon and energy reduction targets through sustainable principles and practices, it is vital to enable long-term changes in stakeholders' attitudes and behaviours whilst promoting positive commitment. Lorenzoni et al. (2007) proposed that commitment concurrently involves cognitive, affective and behavioural aspects at an individual level to embrace wider values embedded within the organisational culture as it relates to $\mathrm{SC}$ principles and practices. 
Sustainable construction practice: With a clear sustainability strategy, stakeholders should identify and select their specific SC practices to assume their commitments. Perera et al. (2007) argued that sustainable practices should consider the environmental, social, and economic consequences of design; manufacture and production methods; non-renewable material use; logistics; recycling options; use; operation; maintenance; reuse; suppliers' capabilities; and service delivery and disposal. DTI (2006) outlined key SC practices, namely: establishing effective construction programmes; developing and supporting well focused and capable public sector clients; designing and decision- making based on 'whole-life value'; using the appropriate procurement and contracting strategies; working collaboratively with fully integrated teams; evaluating performance, and embedding project learning. Sustainable design has a significant impact on project sustainability before construction begins. SC practices include five major areas: 1.compliance with sustainability legislation 2.design and procurement technology and innovation 3.organizational structure and process 4.education and training 5.measurement and reporting. Different organisations' characteristics will lead to different choices in SC practices. The stated SC practices should be consistent with the all-encompassing strategy. Firstly, compliance with sustainability legislation will sacrifice company profit. However, better regulation will provide the right balance between regulation and environmental protection without extremely increasing costs or preventing compliance (HMG, 2008). Secondly, sustainable design has a significant impact on project sustainability before construction begins. Sustainable procurement provides a green supply chain system where all the materials and equipment are supplied in a green manner (Vanegas, 2003). Thirdly, technology research and development (R\&D) plays an important role in the SC and effective R\&D will result in great improvement in sustainability performance (Miyatake, 1996). Appropriate organisational structure and process are also necessary to determine responsibilities, authority, lines of communication, process and the resources needed to implement sustainable management systems (Hill and Bowen, 1997). Rajeev and Hewage (2015) argued that a process whereby organisations meet their needs for goods, services, works and utilities in a way that achieves value for money on a whole life basis in terms of generating benefits not only to the organization, but also to society and the economy, whilst minimizing damage to the environment. Fourthly, the importance of education and training for SD has been pointed out by many because it is widespread and changes the way stakeholders think about nature (Huckle and Sterling, 1996). Finally, measurement and reporting provide the proof of business care for SC and also encourage construction organisations to promote their sustainability performance (Pitt et al., 2009).

Sustainable construction principles: There are numerous studies on the subject of SC. In the typical study by Kibert (1994), SC principle focuses on creating sustainable built environment under six principles: 1) minimize resource consumption 2) maximize resource reuse 3) use renewable or recyclable resources 4) protect the natural environment 5) create a healthy, non-toxic environment and 6) pursue quality in creating the built environment. Hill and Bowen (1997) summarised the principles of SC and divided them into four 'pillars', including social, economic, environmental and technical principles with a set of process-oriented principles. Construction activities need to reduce environmental impact and enhance social and economic contribution (Hill and Bowen, 1997). When stakeholders set up a sustainability strategy, the principles of SC should be embedded in the strategy and appreciated by all stakeholders and employees. The principles of SC govern three main pillars: environmental protection, social well-being and economic prosperity (Shellbourn et al., 2006). Environmental protection concerns both the built and the natural environment. The built environment refers to the activities within the construction project itself, which may, if not handled effectively, have a serious adverse impact on the environment. Environmental sustainability is concerned with the extraction of natural resources (Addis and Talbot, 2001). Social well-being concerns the human feelings: health, security, satisfaction, safety and comfort (Lombardi, 2001) and human contributions: skills, knowledge and motivation (Parkin, 2000). Finally, economic sustainability is concerned with the monetary gains 
from the project for the benefits of the clients, construction players, public and the government (Abidin, 2010). Figure 1 shows the three pillars of sustainability that made up sustainable principles that has been suggested to be considered by key stakeholders in terms of implementation in SC projects/activities.

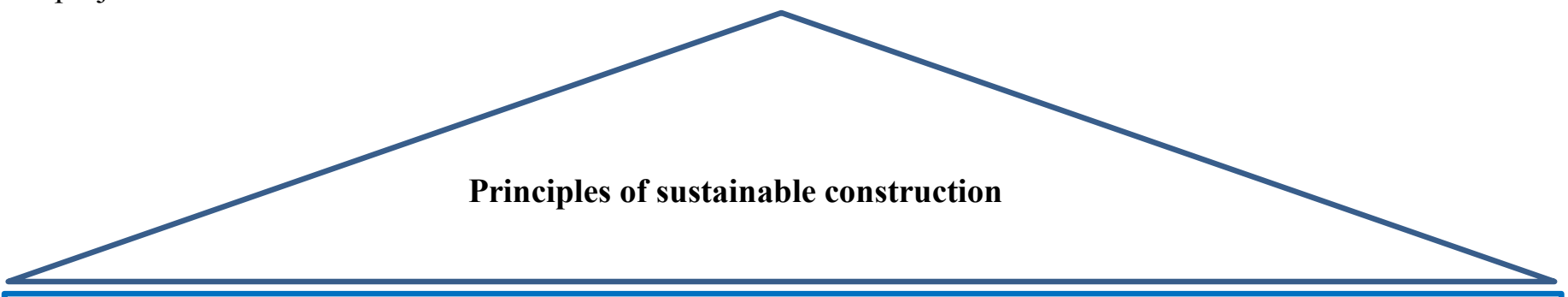

These are main principles indicating approaches to be followed in evaluating the applicability and importance of each 'pillar' and its associated principles, to a particular project.

- Undertake prior assessments proposed activities

- Timeously involve people potentially affected by proposed activities in the decision making process

- Promote interdisciplinary collaborations and multi-stakeholder partnerships
- Recognise the necessity of comparing alternative courses of action

- Utilise a life cycle framework

- Utilise system approach

- Exercise prudence

- Comply with relevant legislation and regulation
- Establish a voluntary commitment to continual improvement of performance

- Manage activities through the setting of targets, monitoring, evaluation, feedback and self-regulation of progress

- Identify synergies between the environment and development.
PILLAR ONE: SOCIAL SUSTAINABILITY

- Improve the quality of human life, including poverty alleviation

- Make provision for social self-determination and cultural diversity in development planning

- $\quad$ Protect and promote human health through healthy and safe working environment

- Implement skills training and capacity enhancement of disadvantaged people

- Seek for fair and equitable distribution of social costs of construction

- Seek equitable distribution of the social benefits of construction

- Seek intergenerational equity
PILLAR TWO: ECONOMIC SUSTAINABILITY

- Ensure financial affordability for intended beneficiaries

- Promote employment creation and, in some situations, labour intensive construction

- Use full-cost accounting and real-cost pricing to set prices and tariffs

- Enhance competitiveness in the market place by adopting policies and practices that advance sustainability

- Choose environmentally responsible suppliers and contractors

- Invest some of the proceeds from the use of non-renewable resources in social and human-made capital, to maintain the capacity to meet the needs of future generations

\section{PILLAR THREE: ENVIRONMENTAL SUSTAINABILITY}

- Extract fossil fuels and minerals, and produce persistent substances foreign to nature, at rates which are not faster than their slow redeposit into the earth's crust.

- $\quad$ Reduce the use of four generic resources used in construction, namely, energy, water, materials and land.

- Maximise resources reuse, and /or recycling

- Use renewable resources in preference to non-renewable resources

- Minimise air, land and water pollution at global and local levels

- Create a healthy and non-toxic environment

- Maintain and restore earth's vitality and ecological diversity

- Minimise damage to sensitive landscapes including scenic, cultural, historical and architectural

Figure 1 Principles of sustainable construction (Adapted from Hill and Bowen, 1997) 
METHODOLOGY: In order to gain an in-depth understanding of the current status of sustainable principles and practices in UK construction, an online questionnaire survey study was conducted. Questionnaire as a research method is a moderately inexpensive way to reach a wider range of respondents (Holyk, 2008). The questionnaire was developed based on the relevant literature. The questionnaire in this study included questions related to how the construction stakeholders value sustainable principles and practices in construction activities. The central limit theorem in statistics specifies that sample size should be at least thirty (30) then sampling distribution is approximately normal (Levine et al., 2011). Therefore the target response rate for the questionnaire was thirty (30) responses. However, a total of one hundred and forty (140) emails were sent to the identified construction organisations. The responses were received within one to eight weeks. Within that period reminder emails were sent. Responses were received from more than seventy (70) construction organisations in the UK. The response rate represents about $75.60 \%$ of the total number of emails sent to the construction organisations.

Questionnaire design: A two-part questionnaire was designed to collect key stakeholders' opinions on promoting and improving sustainable principles and practice. Part I, which was designed to collect the demographic information of respondents, e.g. company type and positions of the respondents in their various organisations. In Part II, respondents were asked to rate the UK construction industry with regards to improving sustainable principles and practices.

RESULT AND DISCUSSION: Figure 2a highlights the respondent's organisation. It depicts the kind of construction activity the organisation which respondents represent engage with. From the result, it is clear that all professions in the construction organisations are represented in the study. The 'Others' in the figure indicated more services that were not enumerated in the choice of answers. The 'others' include: private and public clients; construction training providers; government sponsored construction organisations; social housing refurbishment contractor; renovation specialists; construction membership organisation and qualifying body; basement excavation; smart building systems integrator.

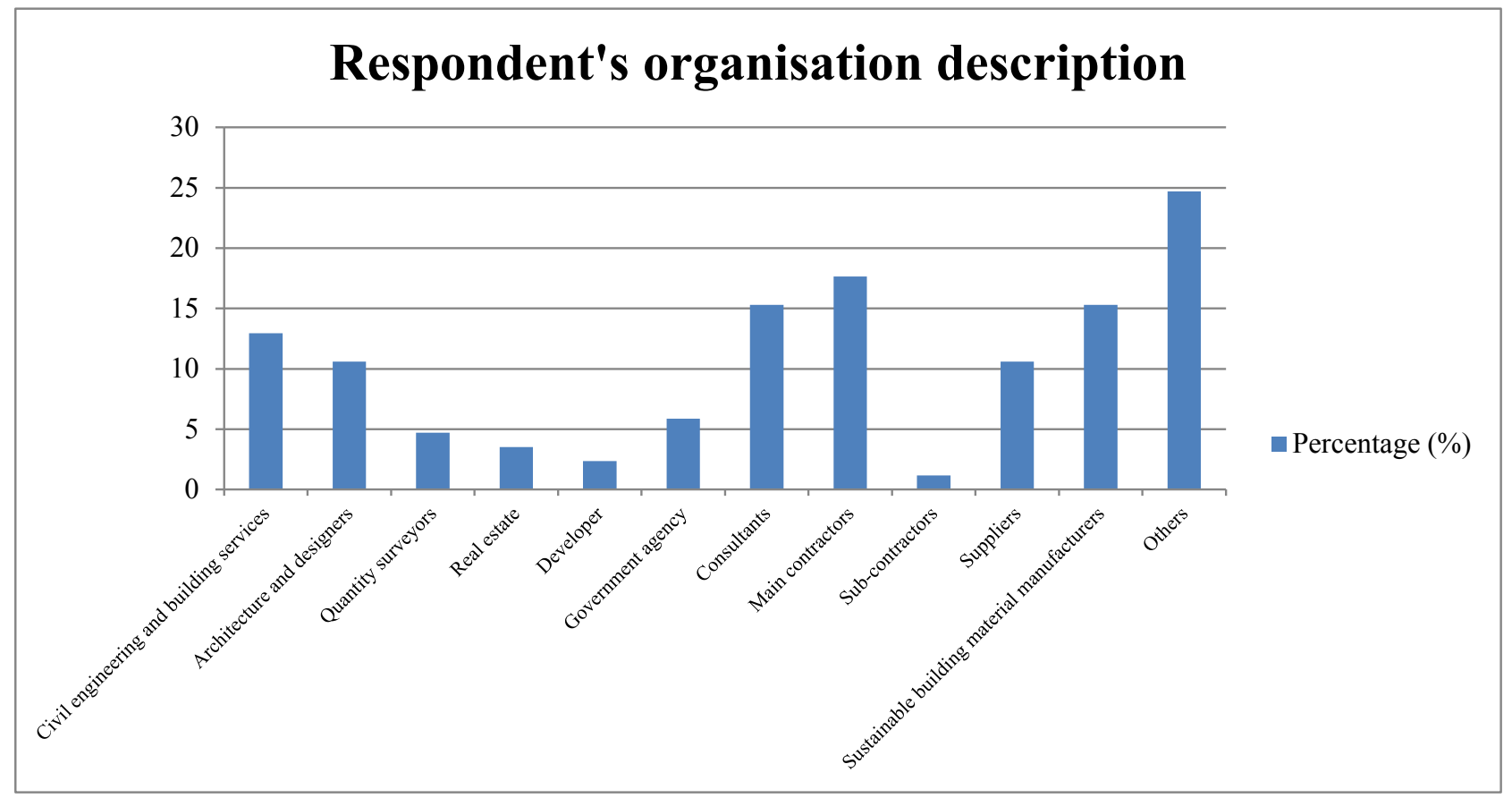

Figure 2a respondents organisation description 
Fig. $2 \mathrm{~b}$ represents the position of the respondents in their various organisations. This shows that the respondent's positions cut across every level of management representation in construction organisations hence the relevance of the survey result aim.

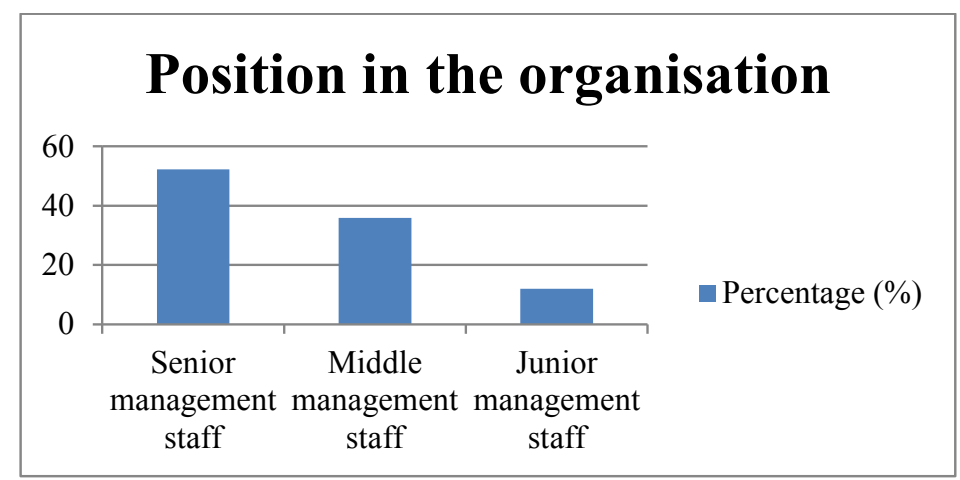

Figure $2 \mathrm{~b}$ Position in the organisation

As indicated in the figure, $52.24 \%$ of the respondents are senior management staff, 35.82 percent middle management staff and $11.94 \%$ are junior management staff. In Figure 3 respondents were asked how the industry stakeholders value sustainable principles and practices in sustainable projects. The results highlight that $5.56 \%$ of respondents representing four respondents stated that the industry promotion of sustainable principles and practices is very poor, $27.78 \%$ representing twenty respondents indicated that the construction stakeholder's value for sustainable principles and practices is poor while $50.00 \%$ representing thirty-six of the respondents stated that the construction industry value for construction principles and practices is moderate.

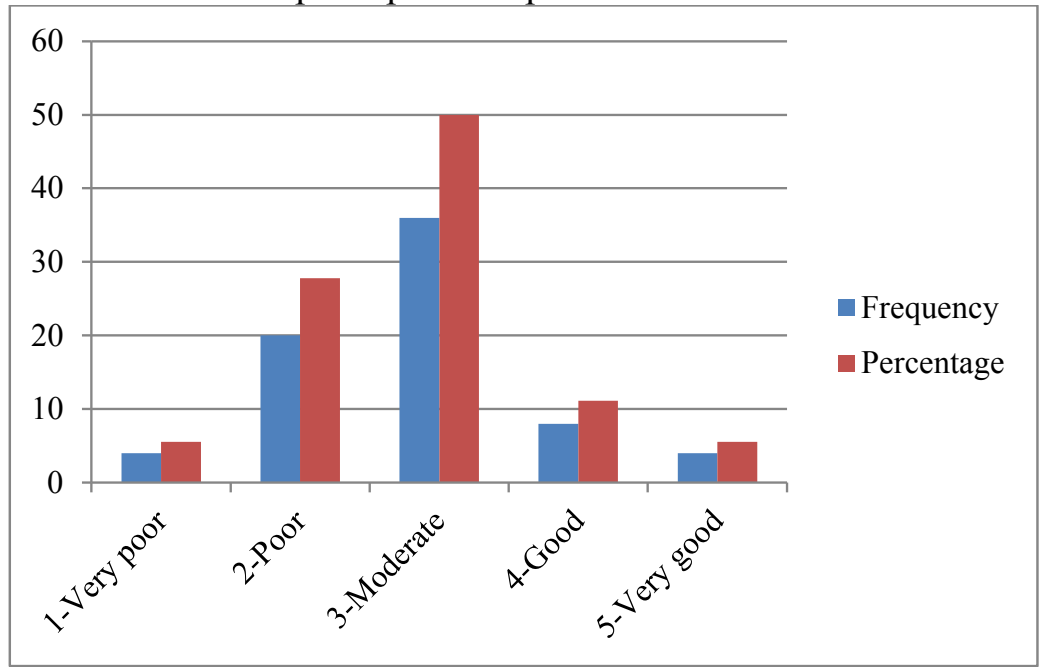

Figure 3 Respondents' rating of the construction industry as regards to how they value sustainable principles and practices in construction projects.

Also, 11.11\% representing eleven of the respondents stated that the industry value for sustainable principles and practices is good while $5.56 \%$ representing four of the respondents stated that the stakeholders value for sustainable principles and practices are very good. The total number of the respondents on Figure three questions was seventy-six while fourteen of the respondents skipped or avoided the question. 
This empirical evidence is valuable because of the number of varied construction organisations and levels of management represented. From the above results, it is evident that the UK construction industry regards sustainable principles and practices to be below par. It is important to note that there is a great need for the industry to gear up to the challenge of adopting, promoting and implementing sustainable principles and practices in delivering construction projects. This can be achieved if the industry identifies possible champions and/or catalysts for particular tasks in every construction project, assign specific roles within the key stakeholders to ensure the implementation of sustainable principles and practices. The relevance of the industry in attaining SD through SC locally and globally cannot be over-emphasised because of its significance to society. If the UK government's target of $80 \%$ reduction of greenhouse gas by 2050 is attainable then there is a great need for the construction industry to live up to anticipated expectation by implementing sustainable principles and practices in every of its activities because of the impacts of construction and the built environment generally.

CONCLUSION: The connection between construction activities and the environment is well documented. Unfortunately, the industry lags behind other sectors in its response to the problems of the environment. The need for SC principles and practices to be promoted and improved has been documented in this paper and it is relevant that the industry implements them for the relevance of the industry on the world stage. The outcome of the survey results indicates that the industry promotion of sustainable principles and practices is a bit under average is necessary to be considered by the industry key stakeholders in order to improve in promoting sustainable principles and practices in construction activities. Progress can be made only through a concerted effort by the key stakeholders by strategising the way forward and following good-practice guidelines. Key roles will be played by different stakeholders and organisations in several perspectives if this is to be achieved. This can include creating awareness of the need for sustainable principles and practices to be implemented consciously in every construction project. To this end, it is imperative that the implementation of SC principles and practices contribute to the improvement of sustainability performance in the industry and capable of creating competitive advantage. There is a great opportunity to improve the sustainability of construction projects by promoting more sustainable principles and practices during project activities.

References:

Abidin, N. Z. 2010. "Investigating the awareness and application of sustainable construction concept by Malaysian developers.” Habitat International 34, 421-426.

Addis, B. \& Talbot, R. 2001. "Sustainable Construction Procurement: A Guide to Delivering Environmentally Responsible Projects." In: Paper Presented at the CIRIA C571.CIRIA, London.

Brownhill, D. \& Rao, S. 2002. "A sustainability checklist for developments: A common framework for developers and local authorities." Building Research Establishment.

DTI 2006. "Sustainable construction strategy reports 2006". Department of Trade and Industry. Available at http://www.dti.gov.uk/files/file21332.pdf Accessed July 2016.Fadeyi, M. O.,

Jallow, A. K., Anumba, C. \& Dulaimi, M. 2012. "Process management approach for achieving total building performance: Essential requirements for sustainable construction." American Society of Civil Engineers, 174-183.

Hill, R. C. \& Bowen, P. A. 1997. "Sustainable construction: principles and a framework for Attainment." Construction Management and Economics, 15, 223-239.

HMG 2008. "Strategy for Sustainable Construction." Her Majesty Government.

Holy, G. G. 2008. "Questionnaire Design.” Encyclopedia of Survey Research Methods. Sage Publications, Thousand Oaks, CA. 
Huckle, J. \& Sterling, S. 1996. "Education for sustainability.” Earthscan Publications Limited, London.

Kibert, C. J. 1994. "Establishing principles and a model for sustainable construction." In the First international conference of CIB TG 16 on sustainable construction, Tampa, Florida, 6-9 November.

Kibert, C. J. 2008. "Sustainable construction: Green building design and delivery (2nd ed.)." Hoboken, NJ: John Wiley \& Sons.

Levine, D. M., Krehbiel, T. C., Benson, M. L. \& Vishwanathan, P. K. 2011. "Business Statistics, fifth ed.". Dorling Kindersley (India) Pvt. Ltd., New Delhi.

Lombardi, P. I. 2001. "Responsibilities Towards the Coming Generations: Forming a New Creed." Urban Design Studies, 7, 89-102.

Lorenzoni, I., Nicholson-Cole, S. \& Whitmarsh, L. 2007. "Barriers perceived to engaging with climate change among the UK public and their policy implications." Global. Environmental Change, 17, 445-459

Maduka, N. S., Udeaja, C. \& Greenwood, D. 2015a. "Exploring Knowledge Management Principles for Decision-Making in Low-Energy Building for Sustainability in Construction." Proceedings of International Council for Research and Innovation in Building and Construction (CIB) of Joint International Symposium On: Going North For Sustainability: Leveraging Knowledge and Innovation for Sustainable Construction and Development. November 23rd - 25th 2015 at London South Bank University.

Maduka, N. S., Udeaja, C. \& Greenwood, D. 2015b. "Managing Project Knowledge in Delivering Sustainable Retrofitted Buildings: A Decision Support Framework." Proceedings of 12th International Post-Graduate Research Conference (IPGRC), 10-12 June 2015

Miyatake, Y. 1996. "Technology Development and Sustainable Construction." Management in Engineering, 12, 23-27.

Parkin, S. 2000. "Sustainable Development: The Concept and Practical Challenge." In: Paper Presented at the Proceedings of the Institution of Civil Engineers, Civil Engineering.

Perera, O., Chowdhury, N. \& Goswami, A. 2007. "The State of Play in Sustainable Public Procurement.” International Institute for Sustainable Development, Winnipeg.

Petri, L. 2014. "Engaging Construction Stakeholders with Sustainability through a Knowledge Harvesting Platform." Computers in Industry, 65, 449-469.

Pitt, M., Matthew, T., Mike, R. \& Jennifer, L. 2009. "Towards sustainable construction: promotion and best practices." Construction Innovation, 9, 201-224.

Rajeev, R. \& Sewage, K. 2015. "Sustainable procurement in the Canadian construction industry: current practices, drivers and opportunities." Journal of Cleaner Production, 109, 305-314.

Rezgui, Y. \& Miles, J. C. 2011. "Harvesting and Managing Knowledge in Construction: From Theoretical Foundations to Business Applications.” Francis \& Taylor, Spon Press, London.

Shellbourn, M. A., Bouchlaghem, D.M., Anumba, C. J., Carillo, P. M., Khalfan, M. M. \& Glass, J. 2006. "Managing Knowledge in the Context of Sustainable Construction." Journal of Information and Technology in Construction 11, 57-71.

Shen, L.-Y., Tam, V. W. Y., Tam, L. \& Ji, Y.-B. 2010. "Project feasibility study: the key to successful implementation of sustainable and socially responsible construction management practice." Journal of Cleaner Production, 18, 254-259.

Shen, L. Y., Song, S. C., Hao, J. L. \& Tam, V. W. Y. 2008. "Collaboration among project participants towards sustainable construction a Hong Kong study." The Open Construction and Building Technology Journal, 2.

Vanegas, J. 2003. "Road map and principles for built environment sustainability." Environmental Science and Technology, 37, 5363-5372.

Yudelson, J. 2010. "Greening existing buildings." New York: McGraw-Hill-A green source book. 